CERN-TH.5587/89

UWThPh-1989-63

\title{
On Spontaneous CP Violation in the Lepton Sector
}

\author{
W. Grimus \\ Institut für Theoretische Physik der Universität Wien \\ A-1090 Vienna, Austria \\ and \\ H. Neufeld \\ CERN \\ CH-1211 Geneva 23, Switzerland
}

\begin{abstract}
After a general discussion of CP transformations in the lepton sector we apply a class of non-standard CP symmetries to the Zee model. We show that the resulting cases are all equivalent and give rise to a Zeldovich-Konopinski-Mahmoud lepton number and to neutral flavour conservation. The mass, the magnetic moment and the electric dipole moment of the corresponding Dirac neutrino are calculated.
\end{abstract}

CERN-TH.5587/89

UWThPh-1989-63

November 1989 

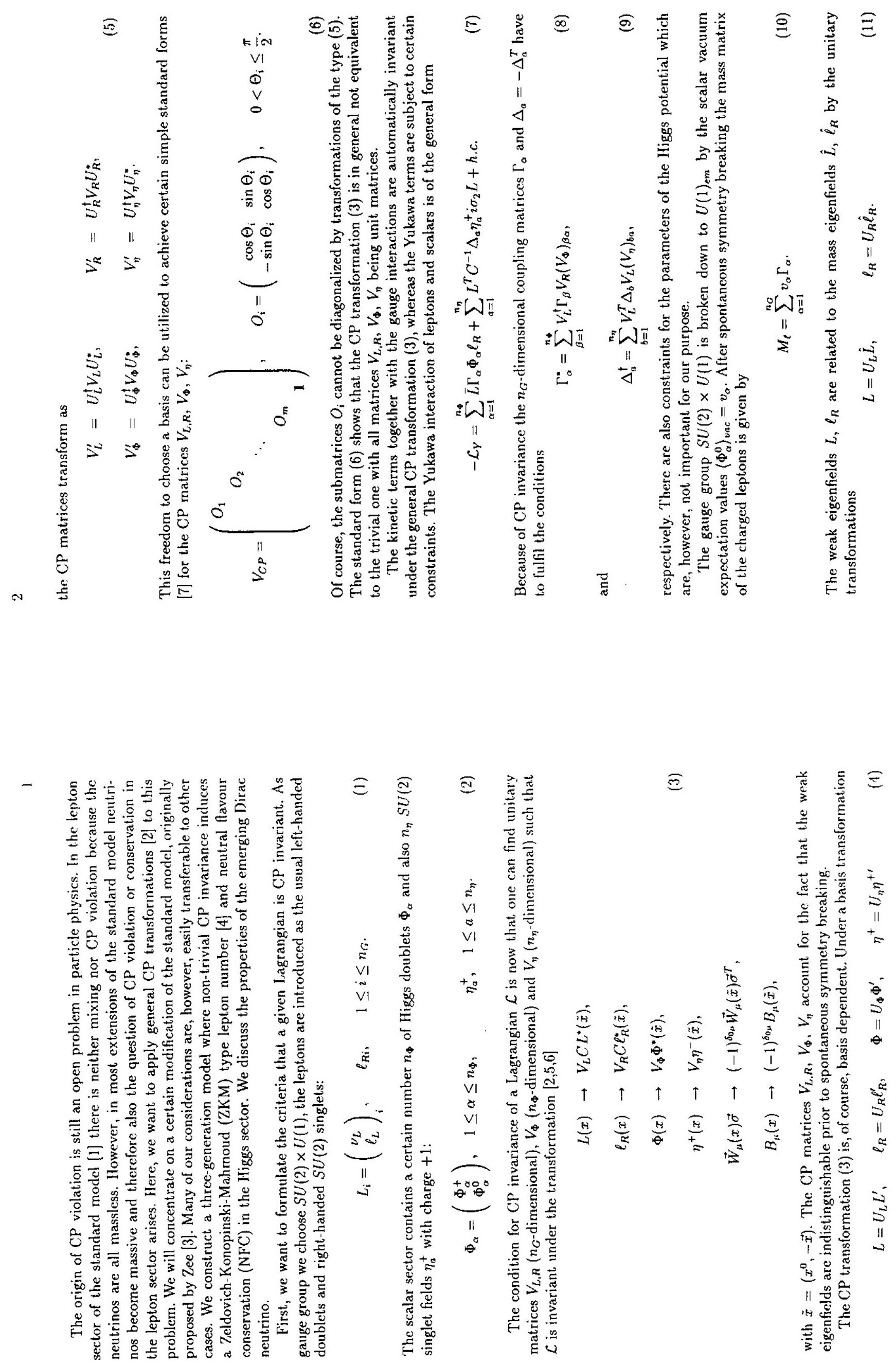


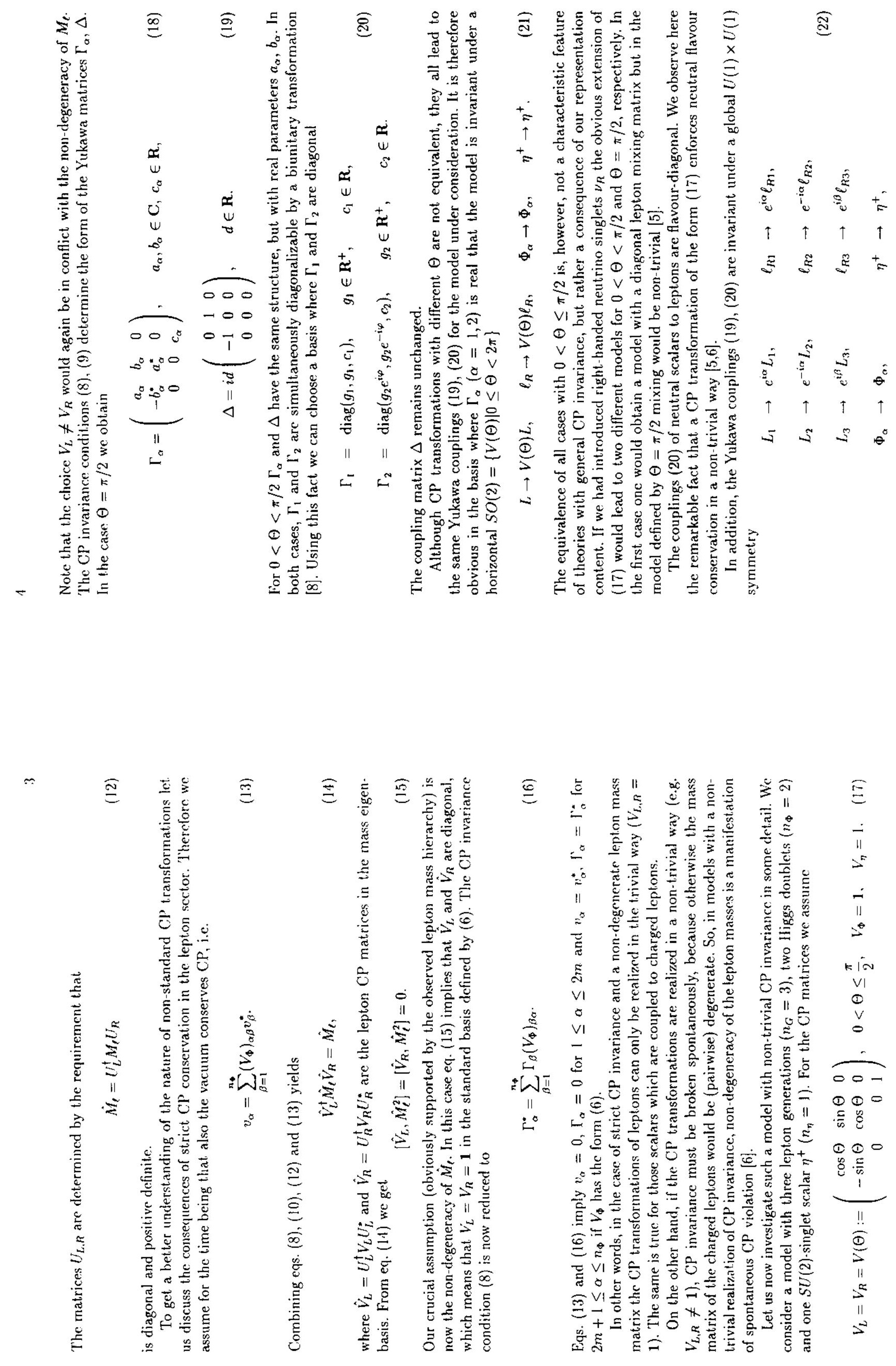




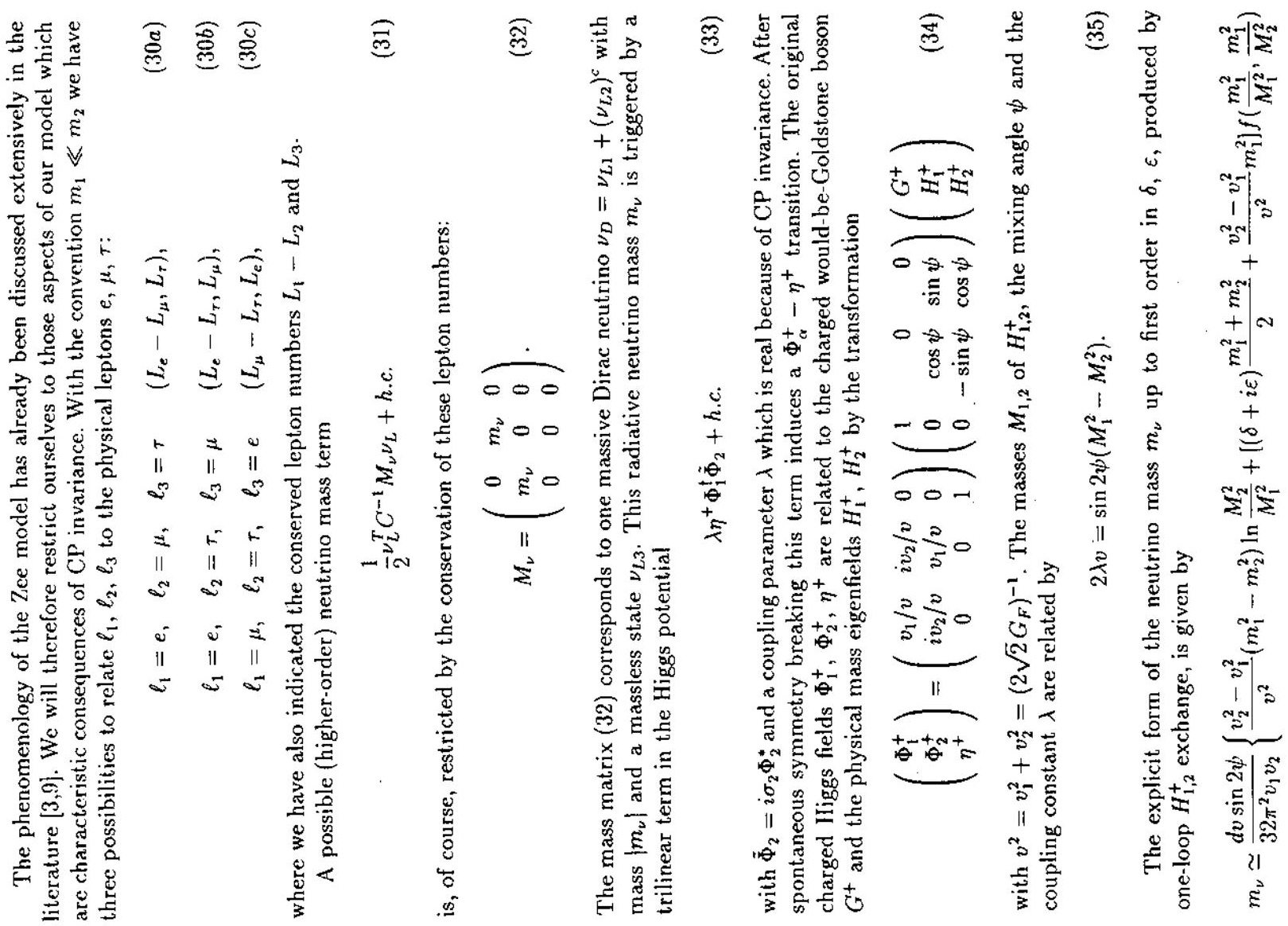

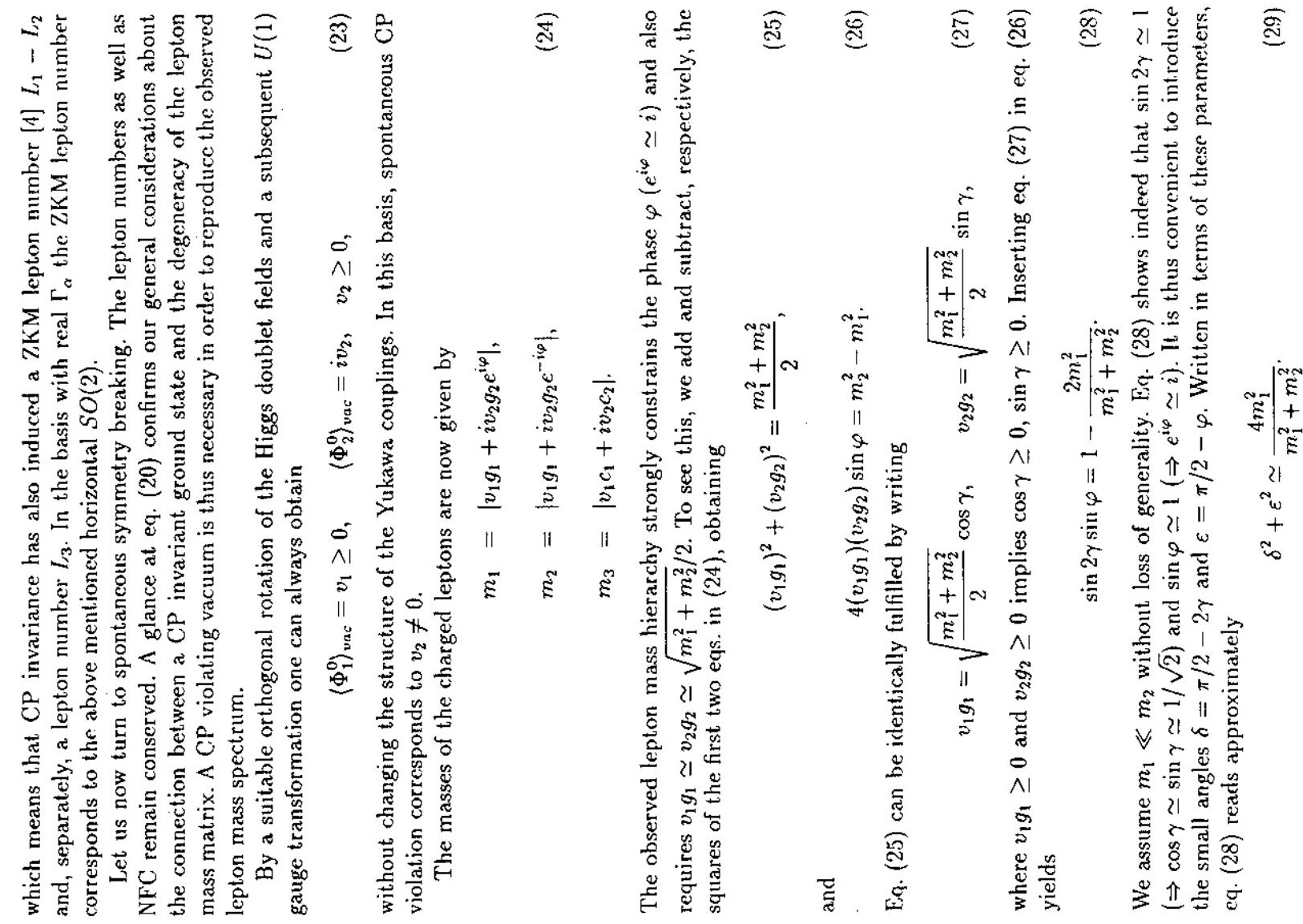



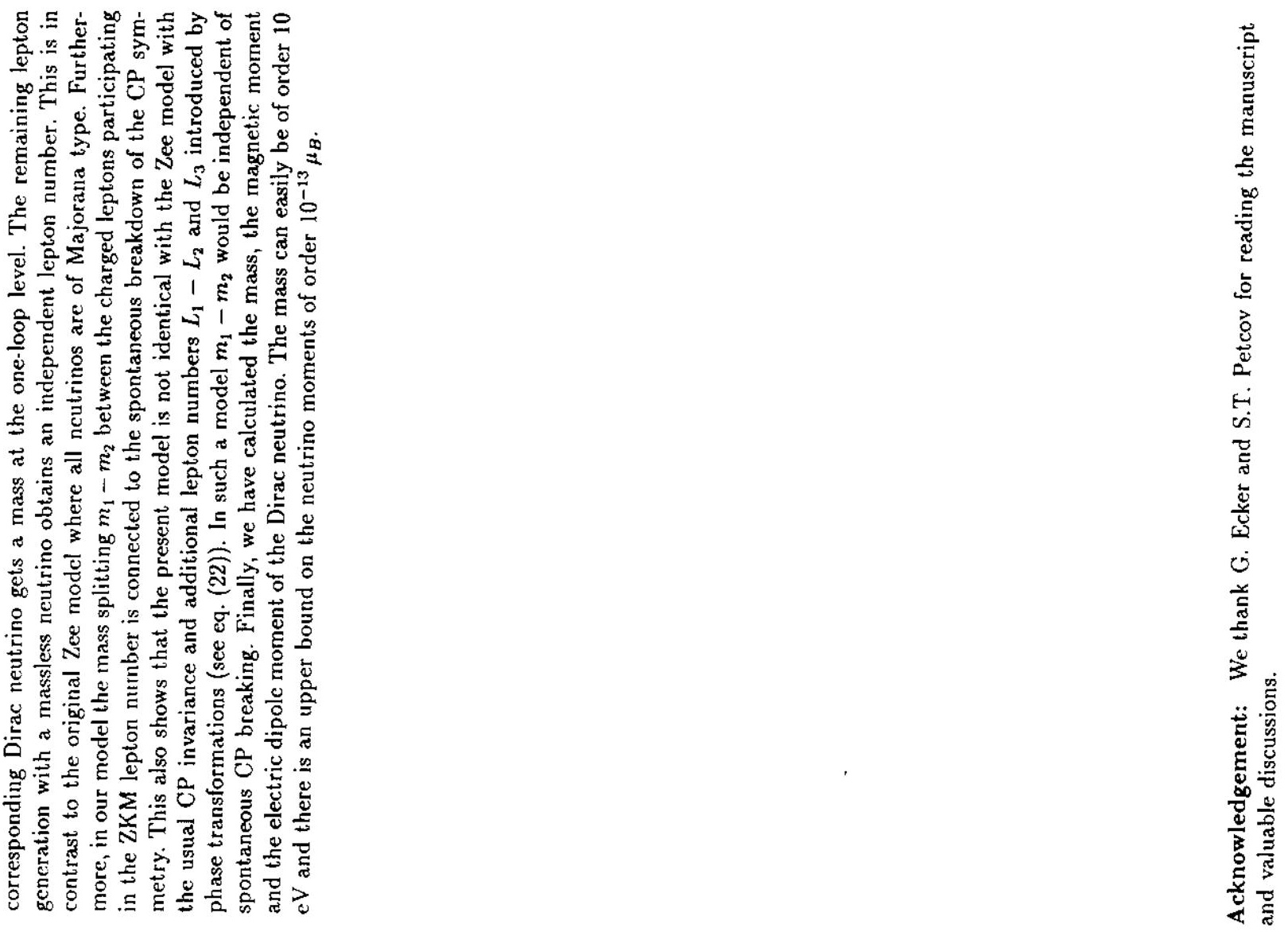

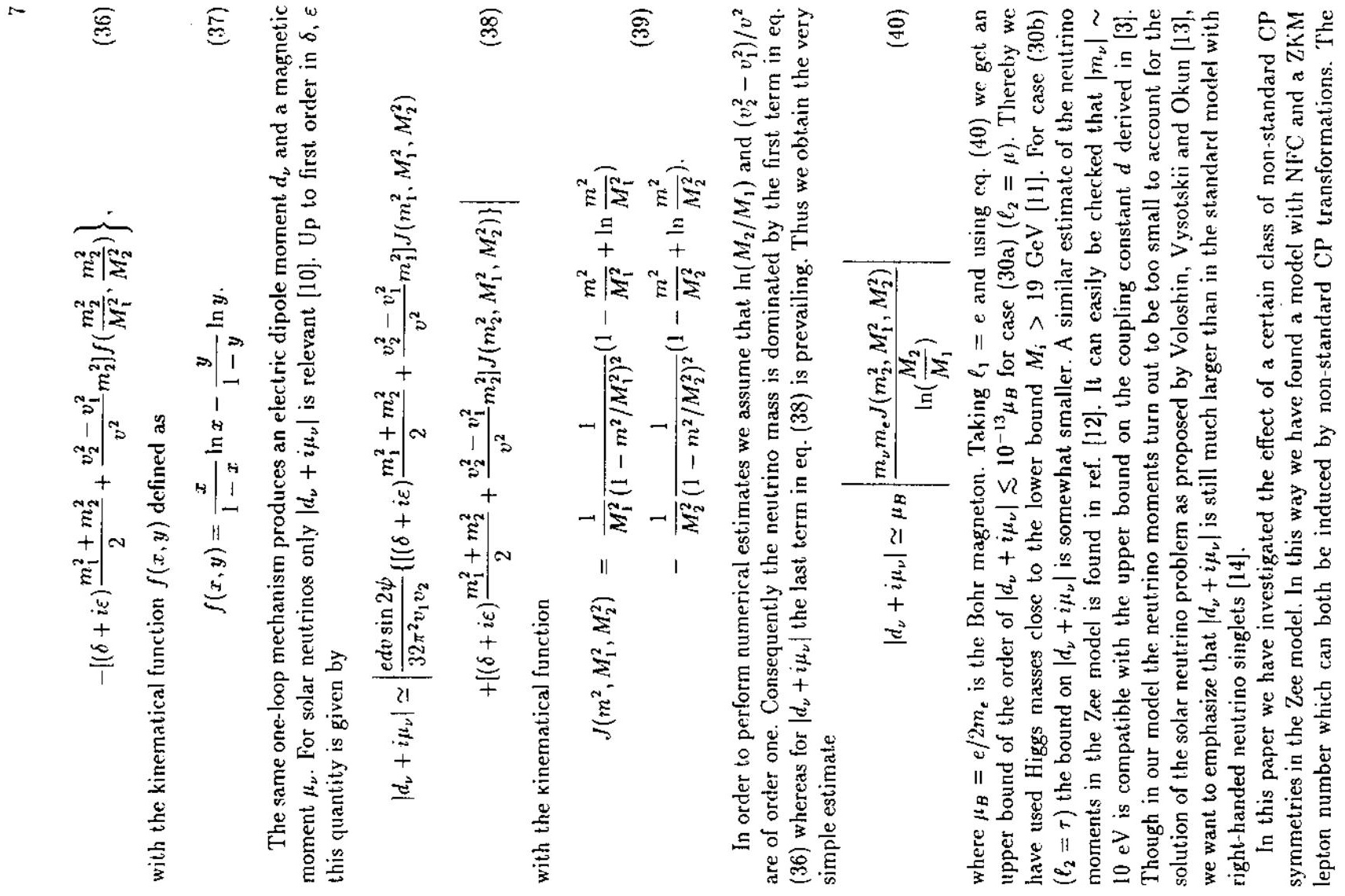




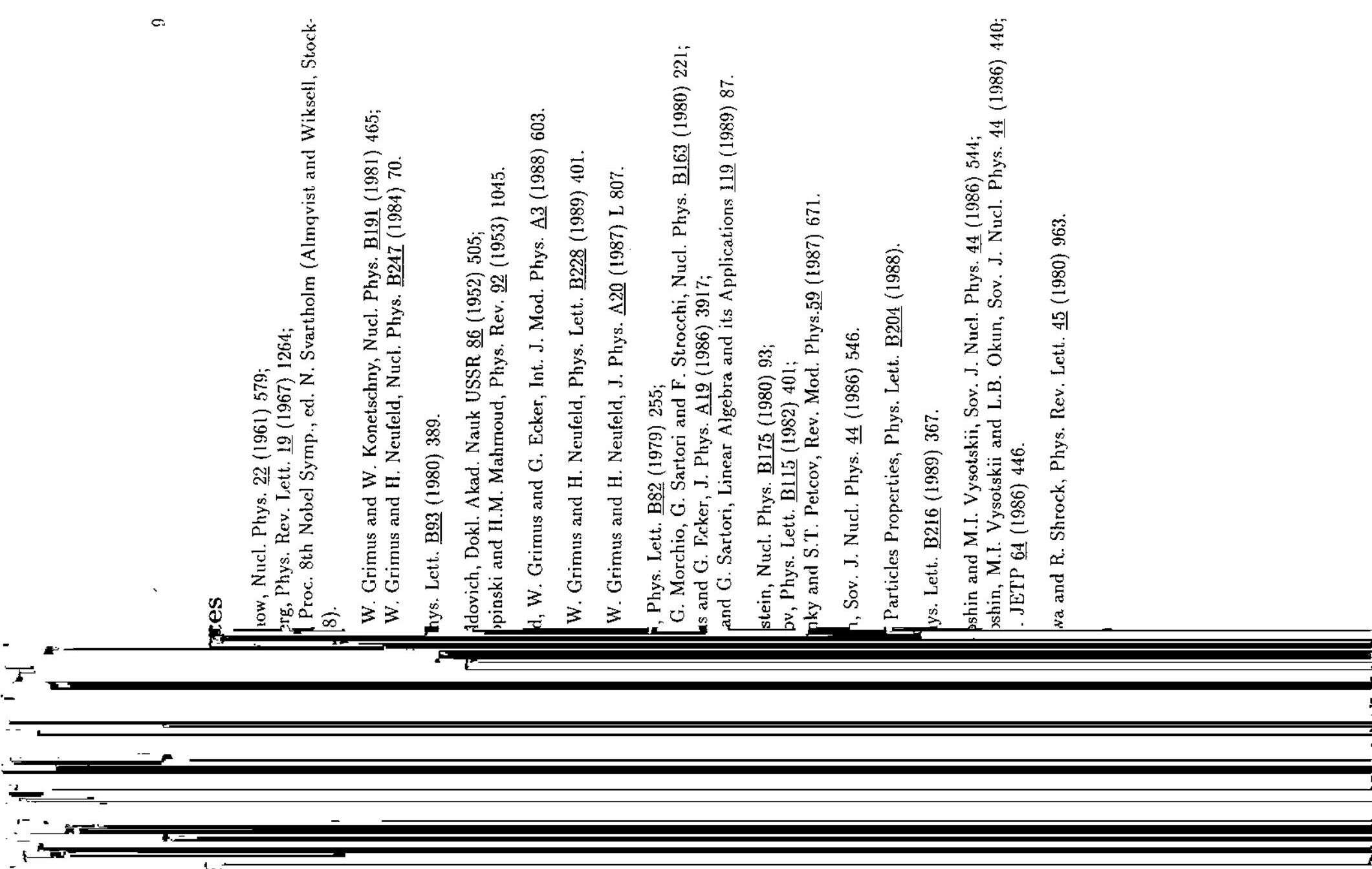




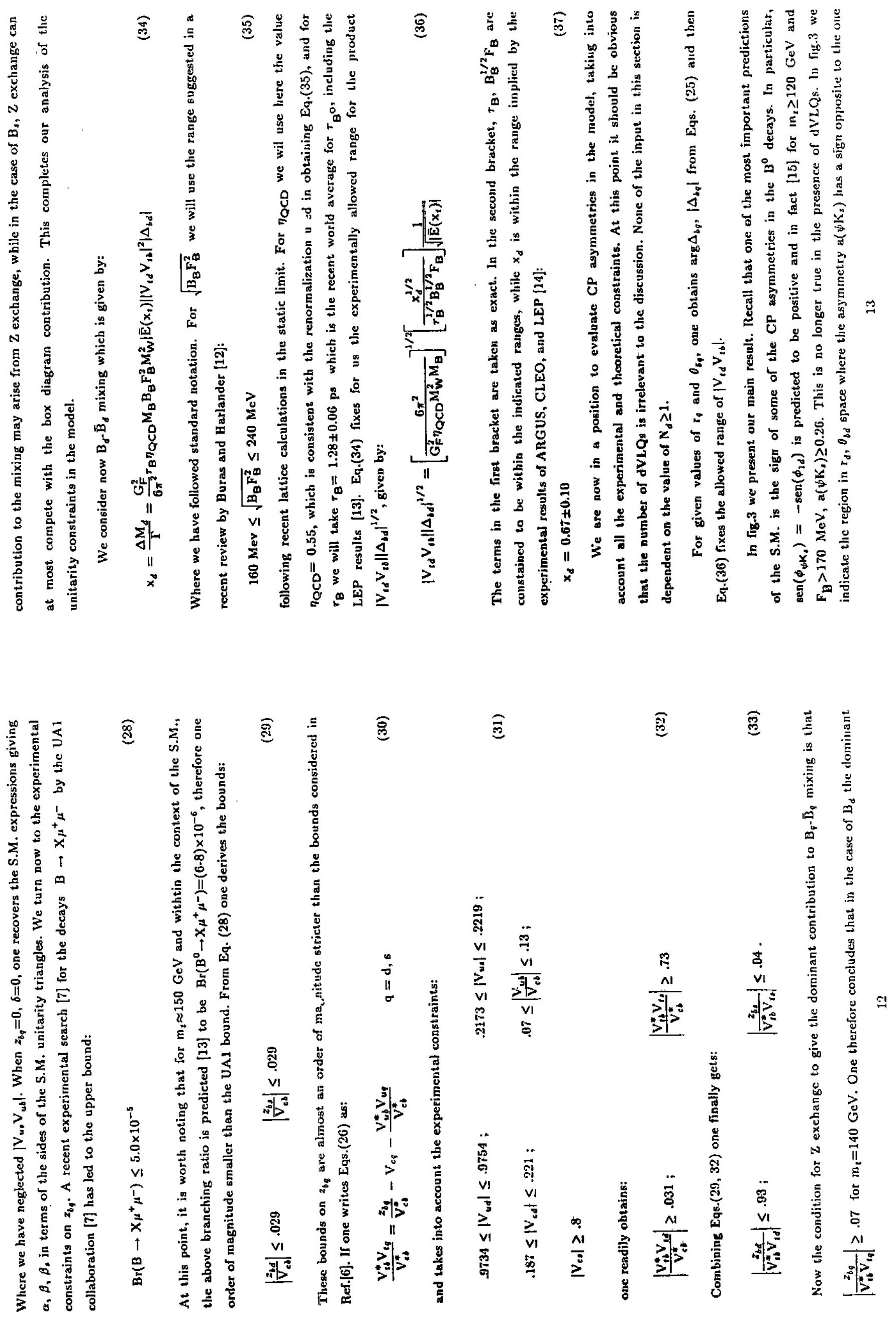




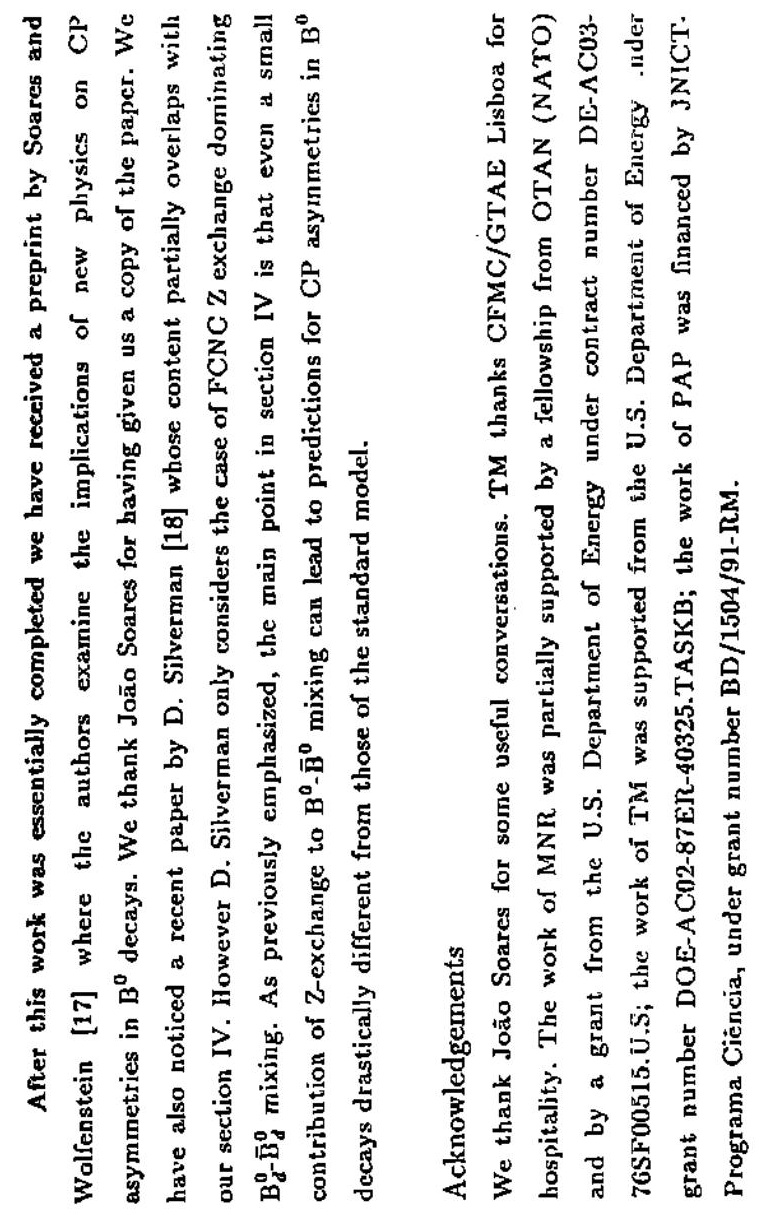

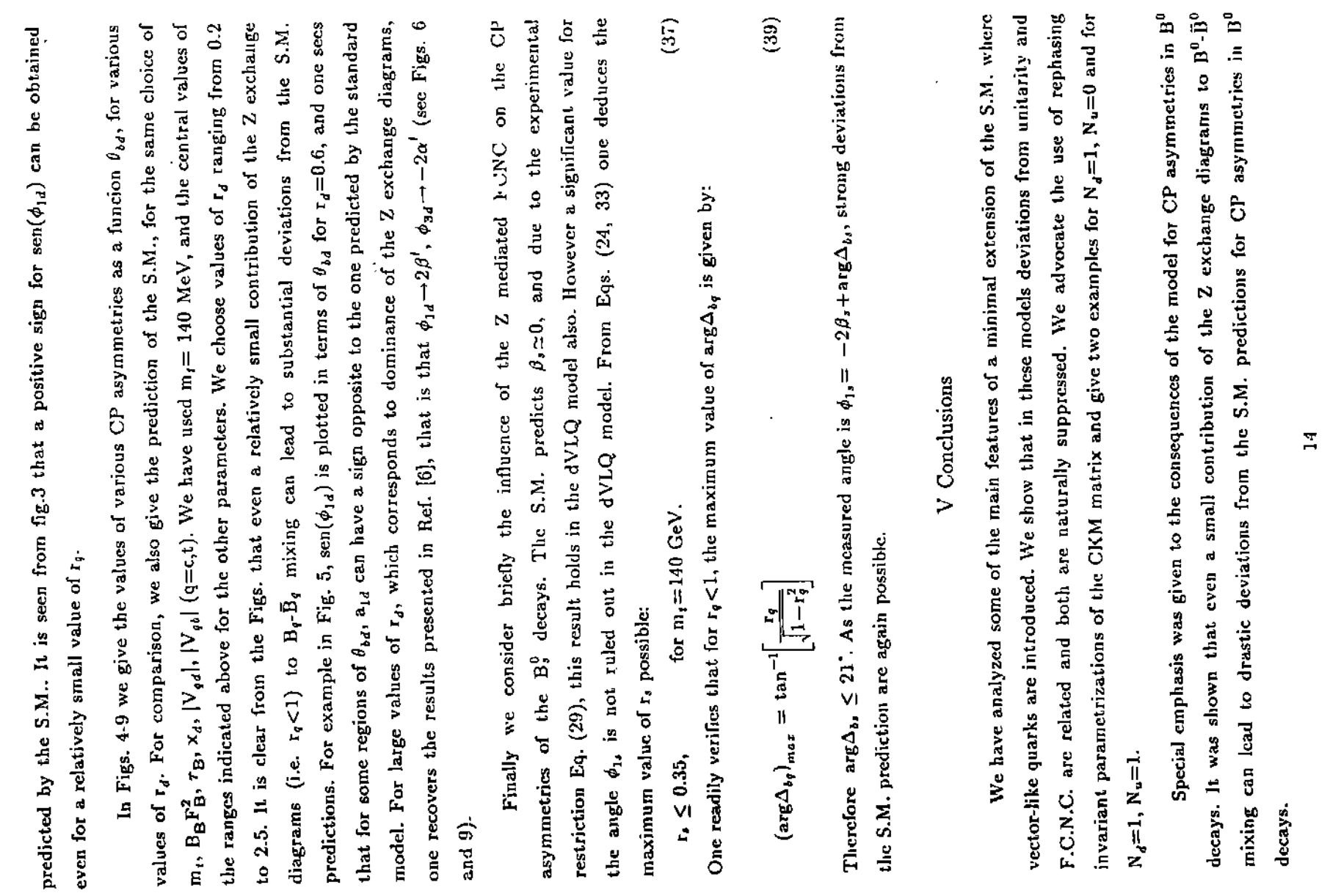



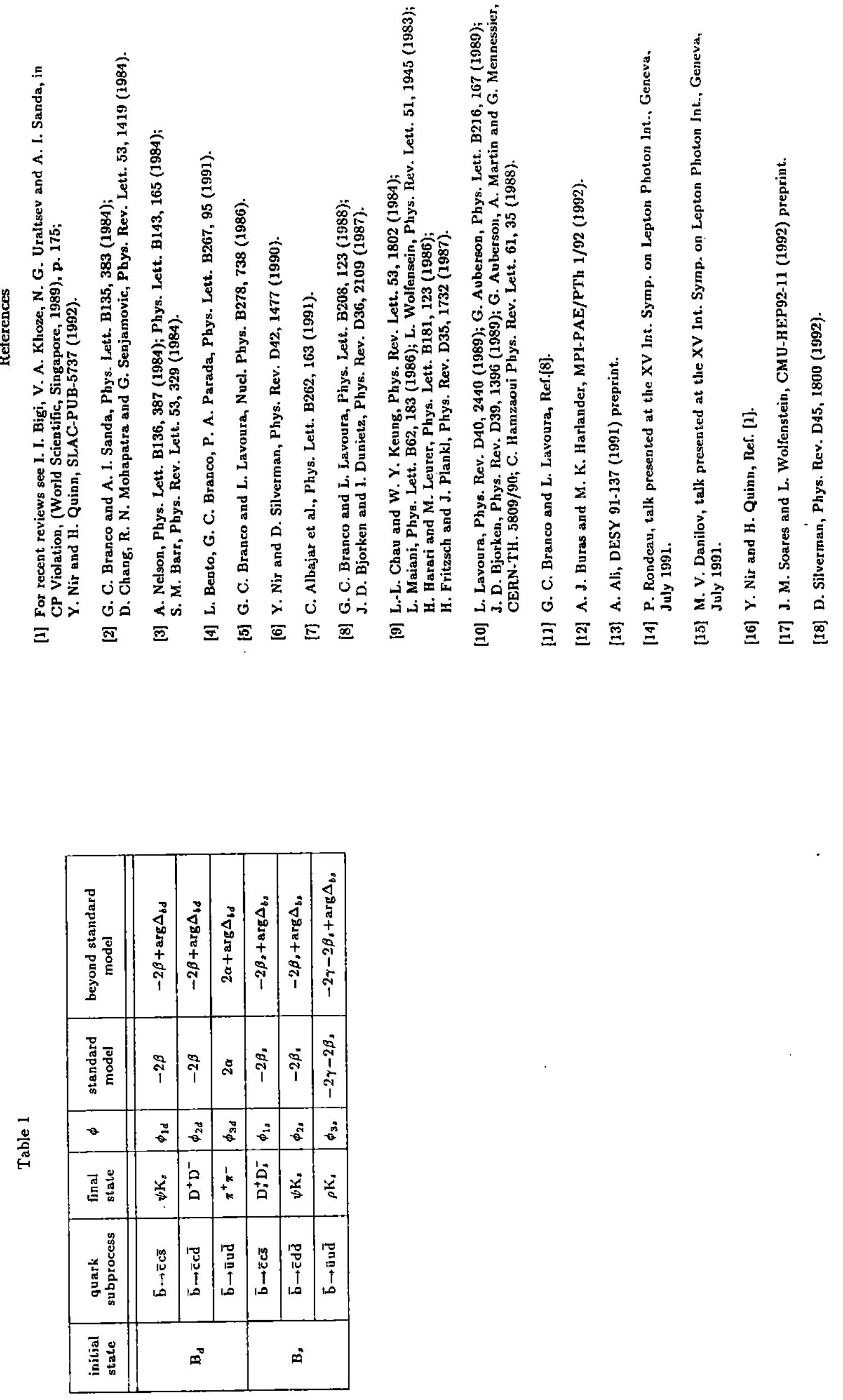


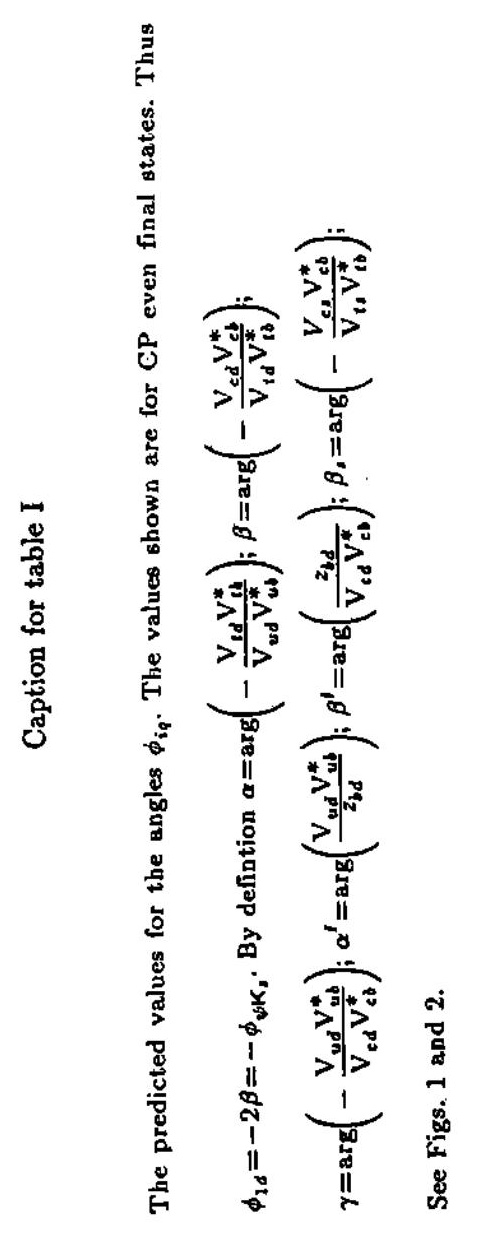

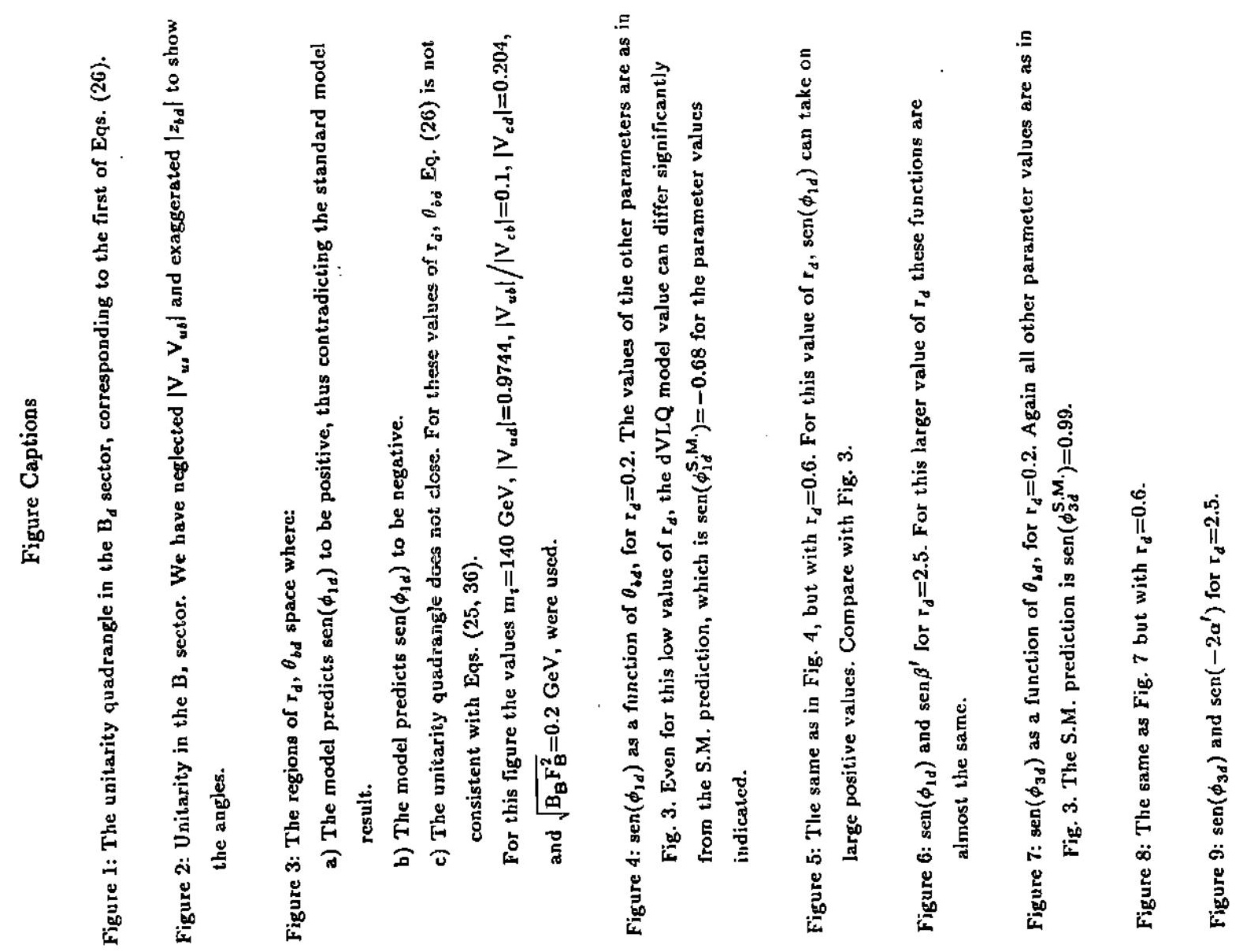




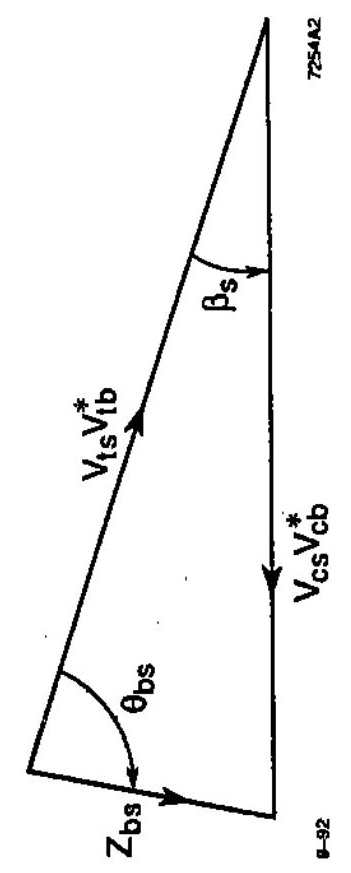

온

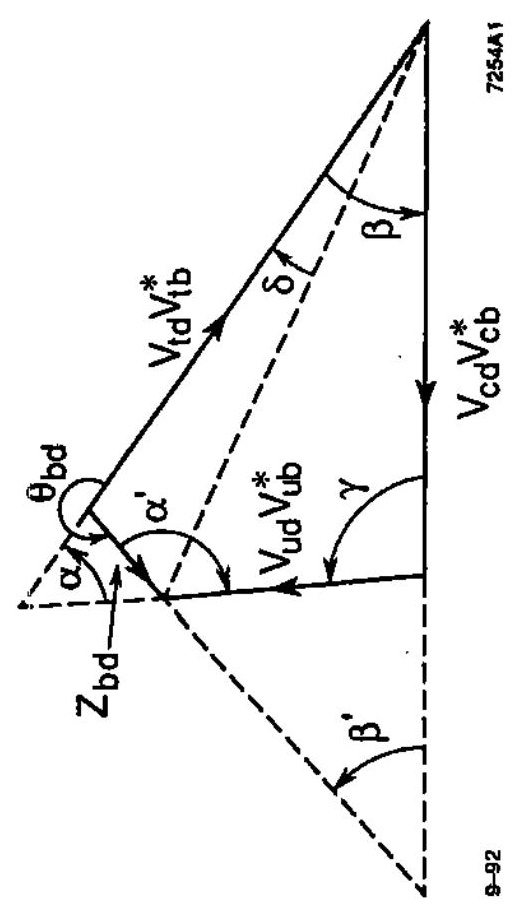

몬 


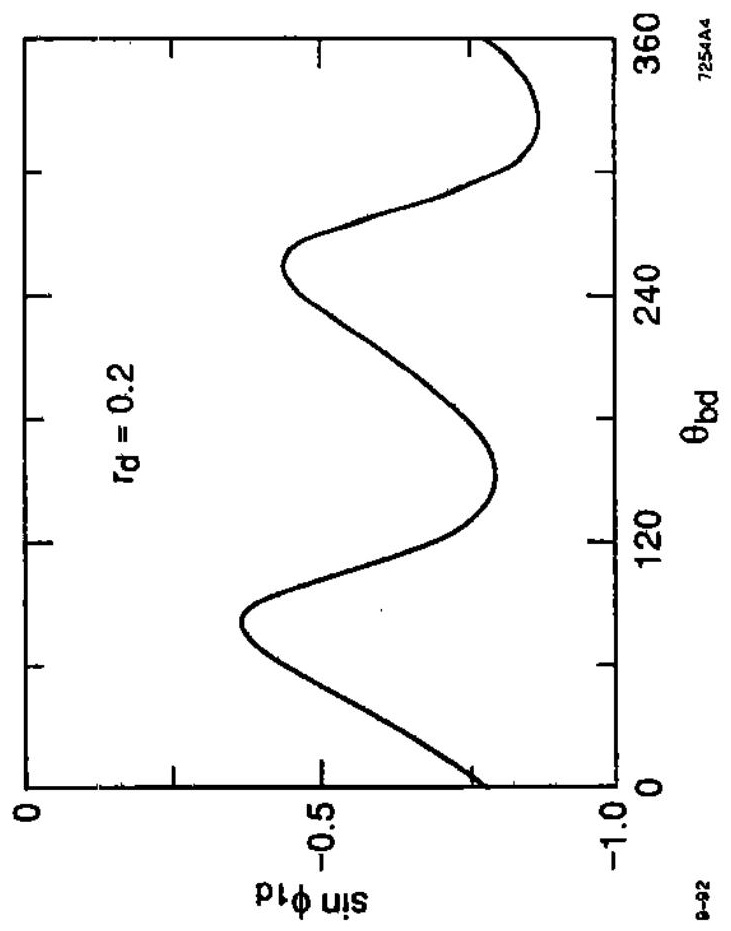

$\stackrel{\nabla}{\dot{\theta}}$

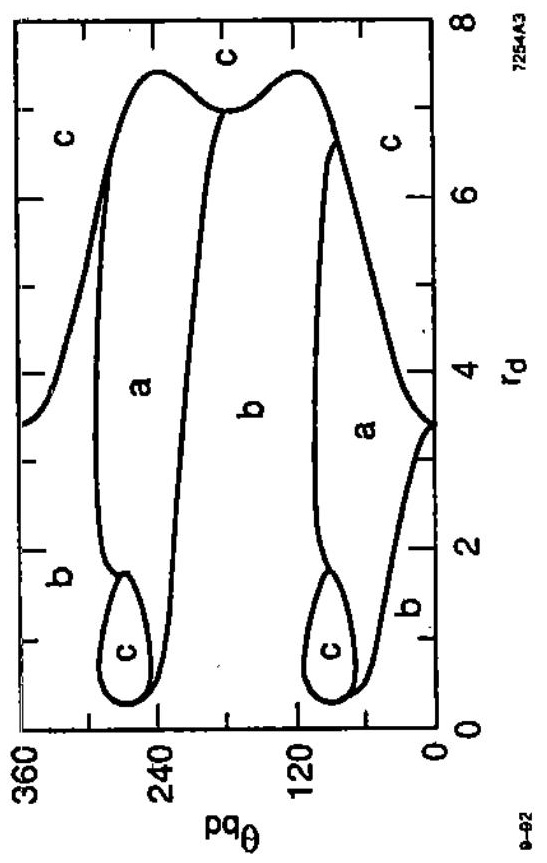

문 

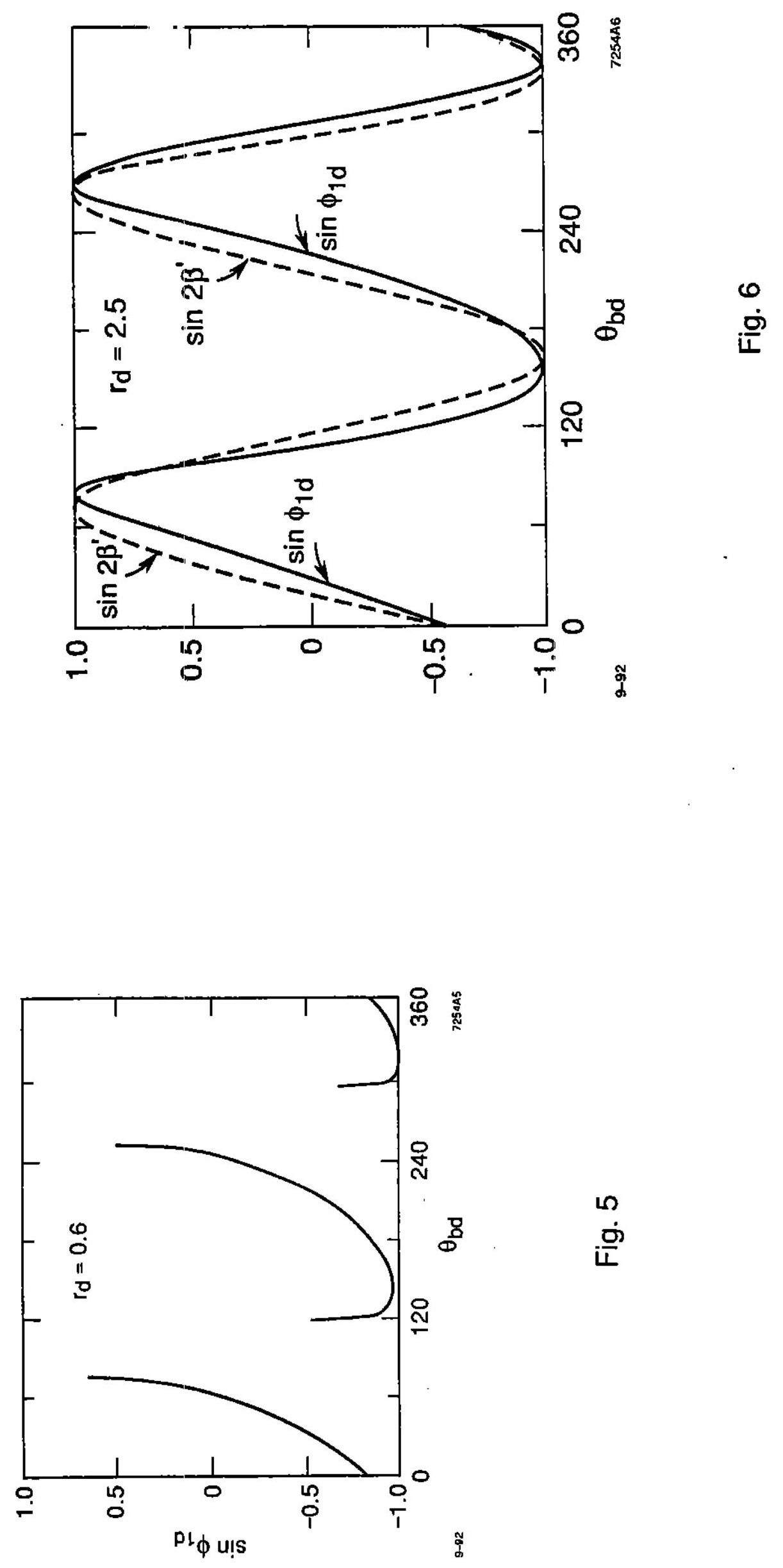

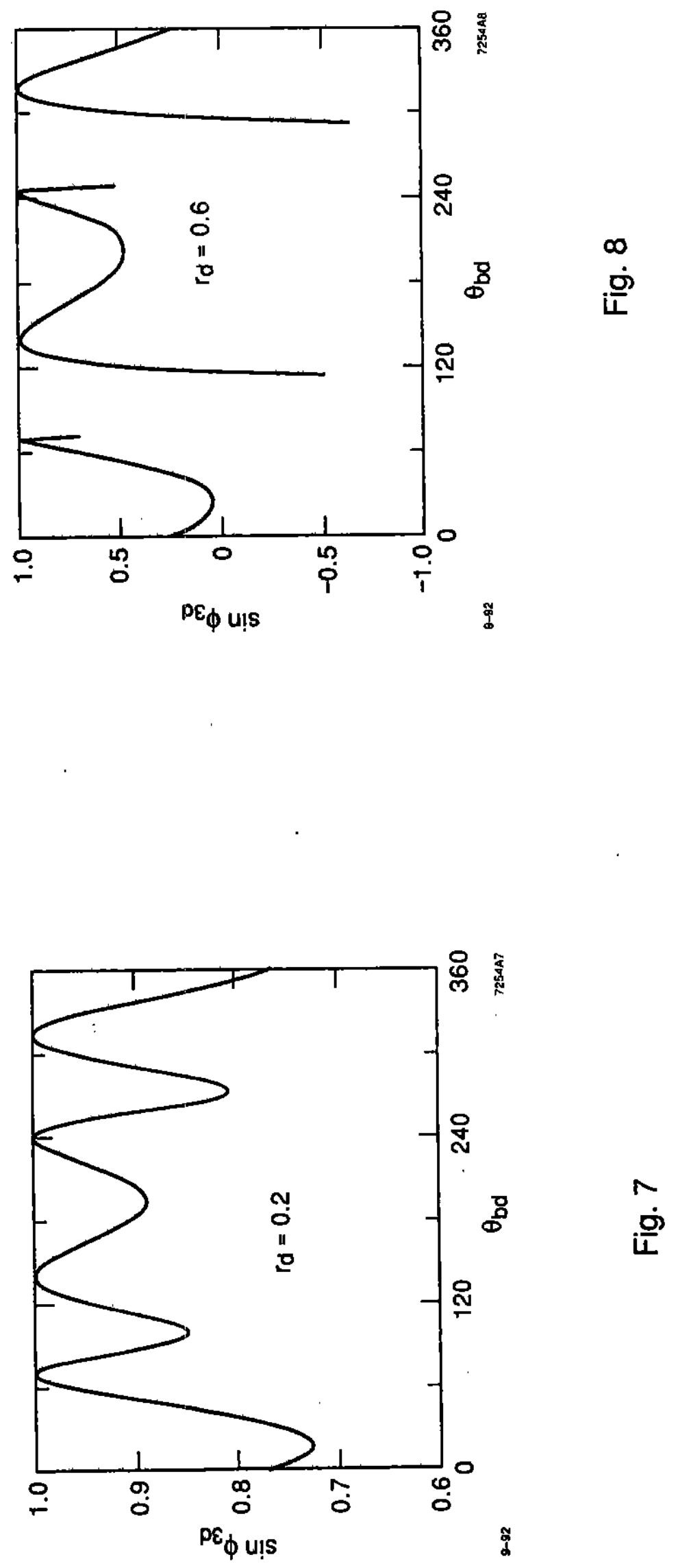


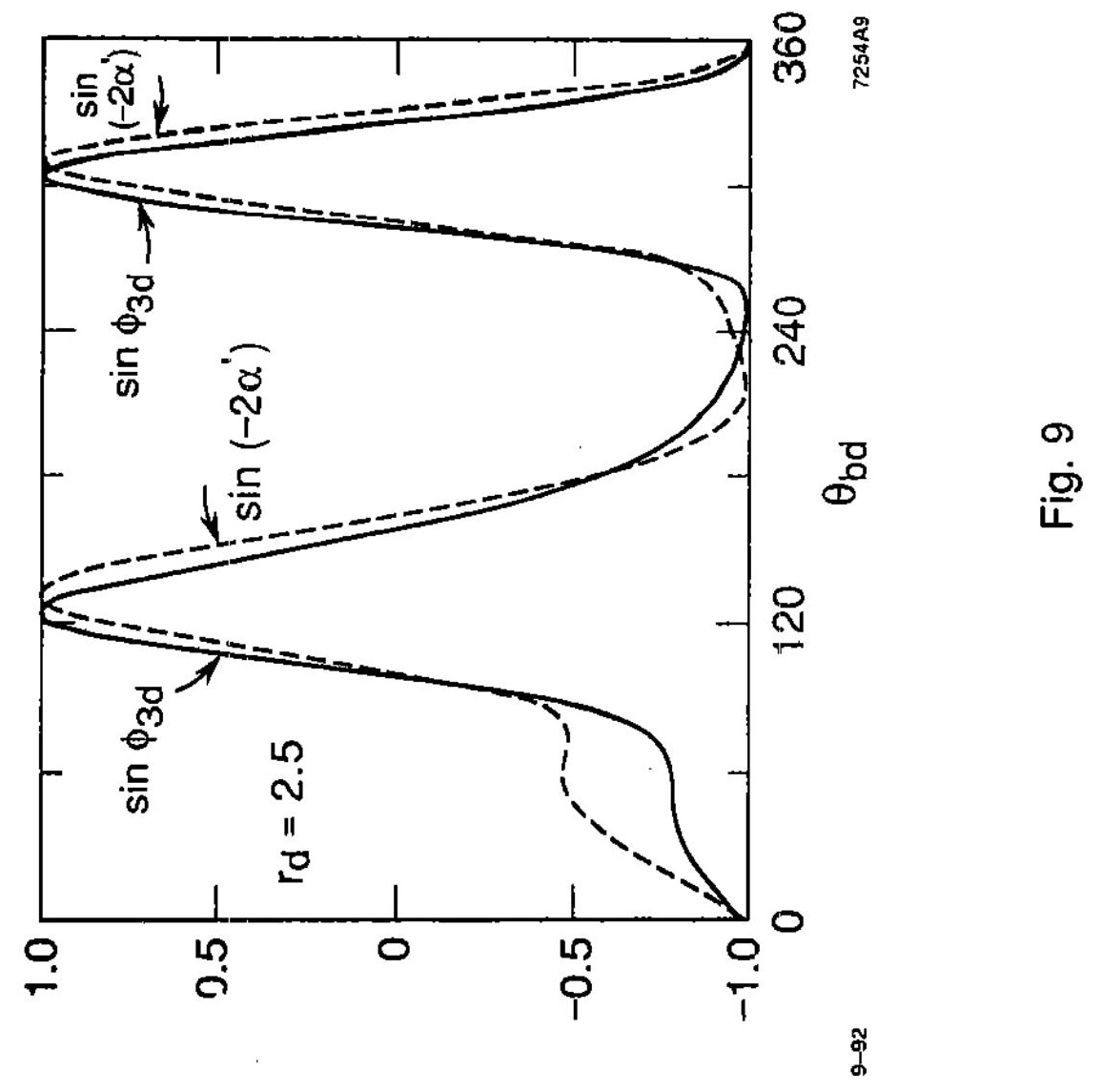

